\title{
Cognitive Emotion Regulation Strategies as Predictors of Academic Achievement among University Students
}

\author{
Ghaleb Al-badareen* \\ Hashemite University, Jordan \\ Received: 19/5/2016 \\ Accepted: 20/6/2016
}

\begin{abstract}
The purpose of this study was to investigate the impact of cognitive emotion regulation strategies on academic achievement of university students in Jordan. A random sample of 386 students from the Hashemite University participated in the current study. The Cognitive Emotion Regulation questionnaire was used to measure the cognitive emotion regulation strategies. The findings of this study showed that cognitive emotion regulation strategies had significant joint effect and relative effect on academic achievement. It is hoped that this study will be beneficial to students and teachers in developing cognitive emotion regulation strategies for effective learning.
\end{abstract}

Keywords: Cognitive emotion regulation strategies; academic achievement, Hashemite University.

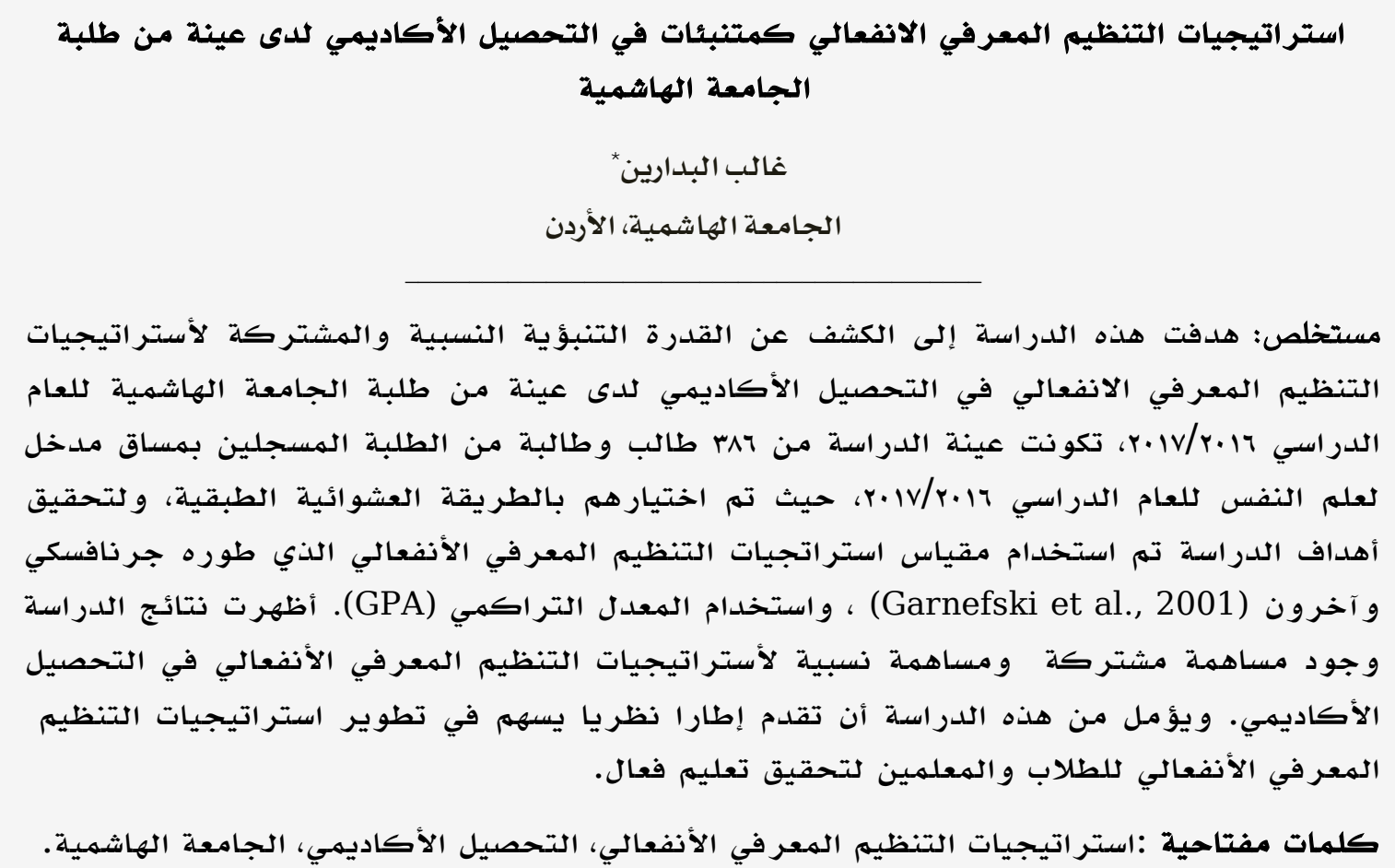

*ghaleb_122@yahoo.com 
In the past few years, there has been a growing realization that emotions influence the learning process both positively and negatively (linnenbrink, 2007). Therefore, attention has been focused recently on developing a deeper understanding of the strategies students use to keep their focus (Corno, 2004). However, research has paid little attention to when and why emotions are associated with academic success, even though emotions involve useful information that can guide one's thinking and actions (Izard, 2005). Emotions, particularly negative emotions, often get in the way of students' learning process. This can occur at the beginning of a learning task - a perceived homework task as boring or overly challenging; or during the task if learners face challenges; or at the end of the task when the learners receive feedback about how they have performed.

From an information processing approach, both positive and negative emotions have imposed load on working memory resources by focusing on the topic of the emotions (Pekrun \& Stephen, 2009). Emotions that are not directly related to a learning task distract attention from the task, thereby reducing cognitive resources available and hindering task performance (Linnenbrink \& Pintrich, 2000). In classroom settings emotional experiences affect learning and performance and influence personal growth in students (Turner, 2006); and can positively or negatively influence motivational processes (Linnenbrink, 2007). Fredrickson (2001) found that students who experience positive emotions generate more ideas and strategies to solve problems. Moreover, Hinton and Fischer (2010) emphasized that cognitive emotion and motivational dimensions of learning are interrelated.

Cognitive emotion regulation refers to the conscious cognitive way of handling the intake of emotionality arousing information (Garnefski, 2001). Cognitive emotion regulation can be considered as part of the general concept of emotion regulation defined as all extrinsic and intrinsic strategies of monitoring, evaluating, and modifying emotional reactions (Gross, 2001).

The term cognitive emotion regulation seldom finds its way on education policy, school reform, or even best teaching practices. The pressing focus on academic demands may contribute to make many policy makers, educators and teachers overlook the importance of embedding the teaching of cognitive emotion regulation in academic context; therefore, making it even more difficult for them to handle academic information (Macklem, 2010). During the last few years, the researchers have shown that the regulation of emotion by cognition or thought is inseparably associated with human life and helps people to keep control over their emotions during or after the experience of stressful events (Garnefski, Teerds, Kraaij, Legerstee, \& van den Kommer, 2003). It is extremely important for teachers to understand the role of cognitive emotion regulation in a student's academic achievement and functioning in the classroom (Kauffman, 2005). Most educators are not aware that teaching cognitive emotion regulation will improve academic performance (Macklem, 2010).

Cognitive emotion regulation for learning consists of the cognitive and motivational processes. The cognitive resources (e.g. attention and cognitive strategies) are influenced by the type of emotions. Positive emotions help students to focus their attention on a learning task and to find creative strategies to solve problems (Perkun, Frenzel, Goetz, \& Perry, 2007). On the other hand, negative emotions distract students' attention from the learning task and focus their attention on thoughts that are irrelevant to the task being performed. The motivational resources for example (interest and commitment) have been influenced by the type of emotion, positive emotions increase learner's interest and their commitment so task learning while negative emotions decrease motivation to learn. Emotion regulation enables learners to have some control over their behavior and remain engaged with learning. Boekaert (2002) noted that students who regulate their emotions were more successful at learning tasks. Gumora and Arsenio (2002) found that early adolescent's emotion regulation make a significant contribution to academic achievement. It has been suggested that ability to modify one's emotions facilitates functioning in academic context (Fried, 2011). On the other hand, the inability to modulate the intensity and duration of one's emotional arousal. it will hinder academic performance (Boekarets, 2011). 
Emotion regulation skills have been associated with greater academic achievement in both cross-section and longitudinal studies (Gumora \& Arsenio, 2002). Graziano, Reavis, Keane, and Calkins (2007) showed that students who scored higher on a measure of teacher-rated emotion abilities had higher scores on literary and math tests. Davids and Levine (2002) showed that reappraisal enhanced memory of educational details. In their study, Villavicencio and Bernardo (2013) showed that students who reported higher levels of both positive emotions and selfregulation obtained higher grades.

There is considerable evidence that cognitive processes are strongly related to achievement; thus, the evidence that negative emotions are linked to these processes is consistent with the notion of mediation (Linnenbrink, 2007). Pekrun, Elliot, and Maier (2009) assumed that negative emotions like anger reduce achievement partly because they negatively affect higher order cognitive processes such as problem- solving, memory, and strategic thinking.

\section{Rationale of the study}

Previous research has indicated the importance of effective emotion regulation in students' academic success, but little work has examined the effectiveness or educational consequences of specific strategies in world as whole. According to the researcher's knowledge, the role of emotional regulation cognitive strategies in academic achievement has not been investigated in the Arab region. Some cognitive emotion regulation strategies are more adaptive than others while learners use different strategies in handling emotional arousal in academic contexts. Therefore, further investigation in this field is needed.

\section{Method}

\section{Participants}

A sample of 386 students was randomly selected from among undergraduate students enrolled in an Introduction to Psychology course offered by the Department of Educational Psychology at the Hashemite University. Participants represented all faculties at the Hashemite University, with 109 (28\%) freshmen, 135 (35\%) sophomores, 77 (20\%) juniors, and $65(17 \%)$ seniors. One the other hand, 178 $(46 \%)$ participants represented scientific faculties and 208 (54\%) represented humanities faculties, with $235(61 \%)$ females and 151 (39\%) males.

\section{Instrumentation}

To evaluate cognitive emotion regulation strategies, Cognitive Emotion Regulation Questionnaire (CERQ) was administered to participants. CERQ was developed by Garnefski, Kraaij, and Spinhoven (2001). Nine cognitive emotion regulation strategies were distinguished within the CERQ on theoretical and empirical bases and each refers to what someone thinks after the experience of threatening or stressful events. Self-blame refers to thoughts of putting the blame for what you have experienced. Other-blame refers to thoughts of putting the blame for what you have experienced on the environment or another person. Rumination refers to thinking about the feelings and thoughts associated with the negative event. Positive refocusing refers to thinking about joyful and pleasant events instead of thinking about actual event. Refocus on planning refers to thinking about what steps to take and how to handle the negative event. Positive reappraisal refers to thoughts of creating a positive meaning to the event in terms of personal growth. Putting into perspective refers to thoughts of brushing aside the seriousness of the event/ emphasizing on the relativity when compare it to other events. Catastrophizing refers to thoughts of explicitly emphasizing the terror of what you have experienced. Finally, acceptance refers to thoughts of accepting what you have experienced and resigning yourself to what has happened

\section{Procedure}

Participants were informed that the purpose of the study was to understand the learning process that each student undertakes. The cognitive emotion regulation questionnaire was distributed and the students were given two weeks to respond to the instrument. Out of 400 students, only 386 completely filled the questionnaire. Descriptive statistics and correlational analysis were utilized to determine the relationships among the outcome measure and the independent variables. Multiple regression analysis was further used in the analysis of the data. 


\section{Results}

Table 1 presents descriptive statistics for all variables. Significant positive relationships ( $p$ $<0.05)$ were found between: acceptance and GPA $(r=0.427)$; positive refocusing and GPA $(\mathrm{r}=0.297)$; refocus on planning and GPA $(r=$ $0.370)$; positive reappraisal and GPA $(r=$ $0.353)$; putting in perspective and GPA ( $\mathrm{r}=$ 0.393). On the other hand, significant negative relationships $(p<0.05)$ were found between: self blame and GPA ( $\mathrm{r}=-0.436)$; rumination and GPA (-0.400); catasrophizing and GPA $(\mathrm{r}$ $=-0.475)$; blaming others and GPA $(r=-0.416)$.

To find out the combined effect of the independent variables: self-blame, acceptance, rumination, positive refocusing, refocus on planning, positive reappraisal, putting into perspective, catastrophizing, and blaming others on academic achievement, simultaneous multiple regression analysis was conducted. The combination of self blame, acceptance, rumination, positive refocusing, refocus on planning, positive reappraisal, putting into perspective, catastrophizing and blaming others significantly predicted academic achievement, $F(9,376)=43.275, p<0.001$. The adjusted $\mathrm{R}^{2}$ was 0.497 indicating that $49.7 \%$ of the variance in academic achievement was accounted for by the combination of the nine variables. Since the most parsimonious models are favored in multiple regression analysis, stepwise multiple regression analysis was conducted on the same data set and the results are shown in Table 2.

Table 2 demonstrates that $49.7 \%$ of the variance of academic achievement of the Hashemite University students is accounted for by the linear combination of nine independent variables, self blame, acceptance, rumination, positive refocusing, refocus on planning, positive reappraisal, putting into perspective, catastrophizing, and blaming others.

Table 1

Means, Standard Deviations, and Inter-correlations for Academic Motivation and Predictor Variables $(\mathbf{N}=386)$

\begin{tabular}{|c|c|c|c|c|c|c|c|c|c|c|c|}
\hline Variables & $\mathrm{M}$ & SD & GPA & 1 & 2 & 3 & 4 & 5 & 6 & 7 & 8 \\
\hline GPA & 2.85 & .55 & & & & & & & & & \\
\hline self blame & 12.8 & 2.95 & $-.436^{*}$ & & & & & & & & \\
\hline acceptance & 13.0 & 3.15 & $.427 *$ & $-.176^{*}$ & & & & & & & \\
\hline Rumination & 13.2 & 3.21 & $-.400 *$ & $.33 *$ & $-.158 *$ & & & & & & \\
\hline positive refocusing & 14.9 & 2.94 & $.297^{*}$ & -.063 & $.243^{*}$ & -.021 & & & & & \\
\hline refocus on planning & 16.1 & 2.73 & $.370^{*}$ & $-.111 *$ & $.300 *$ & $-.094 *$ & $.310^{*}$ & & & & \\
\hline postive reappraisal & 15.0 & 2.88 & $.353^{*}$ & $-.176^{*}$ & $.262 *$ & $-.109^{*}$ & $.225^{*}$ & $.212 *$ & & & \\
\hline $\begin{array}{l}\text { putting into perspec- } \\
\text { tive }\end{array}$ & 13.2 & 2.81 & $.393^{*}$ & $-.341 *$ & $.234^{*}$ & $-.18 *$ & .076 & $.247 *$ & $.277 *$ & & \\
\hline catastrophizing & 10.8 & 3.62 & $-.475^{*}$ & $.362 *$ & $-.246^{*}$ & $.381 *$ & $-.152 *$ & $-.161 *$ & $-.272 *$ & $-.330 *$ & \\
\hline blaming others & 10.7 & 3.67 & $-.416^{*}$ & $.339 *$ & $-.204 *$ & $.260 *$ & $-.227 *$ & $-.127 *$ & $-.312^{*}$ & $-.221 *$ & $.478 *$ \\
\hline
\end{tabular}

Table2.

Stepwise multiple regression analysis summery for cognitive emotion regulation strategies in predicting academic achievement (N=386).

\begin{tabular}{crrrrrrrrr}
\hline Model & $\mathrm{R}$ & $\mathrm{R}^{2}$ & $\begin{array}{l}\text { Adjusted } \\
\mathrm{R}^{2}\end{array}$ & $\begin{array}{l}\text { Std. Error of the } \\
\text { Estimate }\end{array}$ & $\mathrm{R}^{2}$ Change & F Change & $\mathrm{df1}$ & $\mathrm{df2}$ & Sig. F Change \\
\hline 1 & $.713^{\mathrm{a}}$ & .509 & .497 & .396 & .509 & 43.28 & 9 & 376 & .000 \\
\hline
\end{tabular}

${ }^{a}$ Predictors: (Constant), Blaming others, refocus on planning, Rumination, putting into perspective, positive refocusing, acceptance, positive reappraisal, self blame, catastrophizing.

Table 3

Unstandardized and standardized regression coefficients for cognitive emotion regulation strategies in predicting academic achievement $(\mathrm{N}=386)$.

\begin{tabular}{|c|c|c|c|c|c|}
\hline & Unstandardized & & Standardized & & \\
\hline Model & $\mathrm{B}$ & Std. Error & Beta & $\mathrm{T}$ & Sig \\
\hline (Constant) & 2.276 & .249 & & 9.123 & .000 \\
\hline Self blame & -.033 & .008 & -.176 & -4.222 & .000 \\
\hline Rumination & -.032 & .007 & -.184 & -4.549 & .000 \\
\hline Positive refocusing & .022 & .008 & .114 & 2.880 & .004 \\
\hline Refocus on planning & .032 & .008 & .158 & 3.956 & .000 \\
\hline Putting into perspective & .022 & .008 & .113 & 2.750 & .006 \\
\hline Catastrophizing & -.022 & .007 & -.141 & -3.127 & .002 \\
\hline Blaming others & -.016 & .007 & -.103 & -2.375 & .018 \\
\hline
\end{tabular}


To find out the relative effect of self-blame, acceptance, rumination, positive refocusing, refocus on planning, positive reappraisal, putting into perspective, catastrophizing, and blaming others (independent variables) on academic achievement, standardized and unstandardized regression coefficients were conducted to measure how strongly each predictor variable influenced the criterion variable as shown in Table 3.

Table 3 demonstrates that the coefficient of self-blame is -.033 , so for every unit increase in self-blame, .033 unit decrease in the academic achievement is predicted, holding all other variables constant. The coefficient for acceptance is 0.033 , so for every unit increase in acceptance, we expect an approximately 0.033 score increase in the academic achievement, holding all other variables constant. The coefficient for rumination is -.032 , so for every unit increase in rumination, we expect an approximately.032 score decrease in the academic achievement, holding all other variables constant. The coefficient for positive refocusing is .022. So for every unit increase in positive refocusing we expect an approximately .022 increase score in the academic achievement, holding all other variables constant. The coefficient for refocus on planning is .032, so for every unit increase in refocus on planning we expect approximately .032 increase score in the academic achievement, holding all other variables constant. The coefficient for positive reappraisal is .018 , so for every unit increase in positive reappraisal we expect an approximately .018 increase score in the academic achievement, holding all other variables constant. The coefficient for putting into perspective is .022, so for every unit increase in putting into perspective we expect an approximately .022 score increase in the academic achievement, holding all other variables constant. The coefficient for catastrophizing is .022 , so for every unit increase in catastrophizing, we expect an approximately .022 score decrease in the academic achievement, holding all other variables constant. The coefficient for blaming others is -.016, so for every unit increase in blaming others, we expect an approximately .016 score decrease in the academic achievement, holding all other variables constant.

\section{Discussion}

The results of this study revealed that cognitive emotion regulation strategies have a significant joint effect on academic motivation of university students; that is, self-blame ; blaming others; acceptance; positive refocusing; refocus on planning; putting into perspective; rumination; positive reappraisal and putting into perspective have the capacity to predict academic achievement of university students. The study findings indicated that adaptive strategies (acceptance, positive refocusing, refocus on planning, putting into perspective, positive reappraisal, and putting into perspective) have relative effect on academic achievement. That is, every strategy has a positive influence on academic achievement. Every student who has the ability to modulate the intensity and the duration of his/her emotional arousal that he/she experiences during the learning task, particularly the negative emotions, leading to focus his/her attention on the learning task in and to find creative methods for solving problems. This finding is consistent with other research findings (e.g. Villavicencio \& Bernardo, 2013; Fried, 2011; Graziano, Reavis, keane \& calkins, 2007; Perkun et al., 2007; Boekaert, 2002; Davids \& Levine, 2002; Gumora \& Arsenio, 2002). In addition, the less adaptive (self-blame, blaming others, rumination, and catasrophizing) have a relative effect on academic achievement; that is, every strategy has a negative influence on academic achievement; that is, every student has inability to monitor, evaluate and modulate the intensity and the duration of his/her emotional arousal that he/she experiences during the learning task, leading to distracting their attention on the learning task and focusing their attention on thoughts that are irrelevant to the task being performed and using rigid methods to solve problems. This finding is also consistent with previous research findings (e.g. Boekarets, 2011; Linnenbrink, 2007; Pekrun, Elliot, \& Maier, 2009).

\section{Implications}

The present research identifies effective emotion regulation strategies, clarifies the effects of specific strategies on students' academic achievement, and has important implications for designing programs to help students to learn effectively. The acceptance and refocus on planning were found to be a highly effective strategy that allowed students to accept 
negative events and take steps to handle these negative events. The benefits of effective strategies use were especially striking for students who were not very skilled at emotion regulation to begin with. Teachers can and should play a vital role in teaching students through learning and using strategies to help with emotional regulation and creating a positive classroom climate that allows for cognitive emotional skills to be taught alongside academic skills.

\section{Conclusion}

It seems clear that cognitive emotion regulation can be a useful tool for students to enhance their academic achievement. Therefore, policymakers should train teachers on how to regulate students' emotions in their classrooms and the overall emotion climate of these classrooms.

\section{References}

Boekaerts, M. (2011). Emotions, emotion regulation and self-regulation of learning. In B. J. Zimmerman \& D. H. Schutz (Eds.), Handbook of the Self-Regulation of Learning and Performance (pp. 408-425). New York and London: Routledge.

Boekaerts, M. (2002). Bringing about change in the classroom: Strengths and weaknesses of the self-regulated learning approach EARLI Presidential Address, 2001. Learning and instruction, 12(6), 589-604.

Corno, L. (2004). Introduction to the special issue work habits and work styles: Volition in education. Teachers College Record, 106, 1669-1694.

Davis, E. L., Levine, L. J., Lench, H. C., \& Quas, J. A. (2010). Metacognitive emotion regulation strategies: Children's awareness that changing thoughts and goals can alleviate negative emotions. Emotion, 10, 498510. doi:10.1037/a0018428

Felicidad, T., Villavicencio, \& Allan B. I. (2013). Positive academic emotions moderate the relationship between self-regulation and academic achievement. British Journal of Educational Psychology, 83, 329-340.

Fredrickson, B. L. (2001). The role of positive emotions in positive psychology: The broaden-and-build theory of positive emotions. American Psychologist, 56, 218-226
Fried, L. (2011). Teaching teachers about emotion regulation in the classroom. Australian Journal of Teacher Education, 36(3), 117-127.

Garnefski, N., Kraaij, V., \& Spinhoven, Ph. (2001). Negative life events, cognitive emotion regulation and emotional problems. Personality and Individual Differences, 30, 1311-1327.

Garnefski, N., Teerds, J., Kraaij, V., Legerstee, J., \& van denKommer, T. (2003). Cognitive emotion regulation strategies and depressive symptoms: Differences between males and females. Personality and Individual Differences, 36, 267-276.

Graziano, P. A., Reavis, R. D., Keane, S. P., \& Calkins, S.D. (2007). The role of emotion regulation in children's early academic success. Journal of School Psychology, 45, 319. doi:10.1016/j.jsp.2006.09.002

Gross, J. J. (2001). Emotion regulation in adulthood: Timing is everything. Current Directions in Psychological Science, 10, 214219.

Gumora, G., \& Arsenio, W. F. (2002). Emotionality, emotion regulation, and school performance in middle school children. Journal of School Psychology, 40, 395-413. doi:10.1016/S0022-4405(02)00108-5.

Izard, C., Stark, K., Trentacosta, C., \& Schultz, D. (2008). Beyond emotion regulation: Emotion utilization and adaptive functioning. Child Development Perspectives, 2, 156163.

Kauffman, J. (2005). Characteristics of emotional and behavioral disorders of children and youth. New Jersey: Pearson.

Linnenbrink, E. A. (2007). The role of affect in student learning: A multi-dimensional approach to considering the interaction of affect, motivation, and engagement. In P. A. Schutz, \& R. Pekrun (Eds.), Educational psychology series (pp. 107-124). San Diego, CA: Elsevier Academic.

Linnenbrink, E. A., \& Pintrich, P. R. (2000). Multiple pathways to learning and achievement: The role of goal orientation in fostering adaptive motivation, affect, and cognition. In C. Sansone \& J. M. Harackiewicz (Eds.), Intrinsic and extrinsic motivation: The search for optimal motivation 
and performance (pp. 195-227). San Diego, CA: Academic Press.

Macklem, G. (2010). Practitioner's guide to emotional regulation in school-age children. New York: Springer Science + Business Media, LLC.

Pekrun, R., Frenzel, A. C., Goetz, T., \& Perry, R. (2007). The control-value theory of achievement emotions: An integrative approach to emotions in education. In $\mathrm{P}$. Schutz \& R. Pekrun (Eds.), Emotion in education (pp. 13-35). Burlington, MA: Elsevier

Pekrun, R., Elliot, A. J., Maier, M. A. (2006). Achievement goals and discrete achievement emotions: A theoretical model and prospective test. Journal of Educational Psychology, 583-597.

Pekrun, R., \& Stephens, E. J. (2009). Goals, emotions, and emotion regulation: Perspectives of the control-value theory. Human Development, 52(6), 357-365 